\title{
Preoperative Radiological Assessment of The Total Knee Arthroplasty
}

\section{Total Diz Artroplastisinin Preoperatif Radyolojik Değerlendirmesi}

\author{
Atilla Hikmet Cilengir $\odot$, Suat Dursun $\odot$, Kazim Ayberk Sinci $\odot$, Ozgur Tosun $\odot$
}

Cite as: Cilengir AH, Dursun S, Sinci KA, Tosun O. Preoperative radiological assessment of the total knee arthroplasty. Forbes J Med. $2021 ; 2(2): 67-73$.

\begin{abstract}
Total knee arthroplasty (TKA) is a surgery method that can reduce symptoms and restore joint functions. Long-term success of this operation depends on the correct anatomical and mechanical planning before the prosthetic material implantation. Accurate implant alignment together with anatomical balance provides more successful clinical outcomes and longer duration of the prosthetic material. Improper preoperative planning may cause implant loosening and increased load on the knee joint. Conventional radiographs are the most frequently used imaging methods for this purpose. Computed tomography and magnetic resonance imaging may be used in required cases. In addition, computer-aided systems have come into use and successful results have been reported. Early radiographic evaluation is unnecessary after an uncomplicated TKA. Preoperative imaging has several aims such as to assess the severity of the disease, to analyze the reserve bone tissue, to review the relevant anatomy, and to decide which implant and surgical approach will be applied. In this article, we aimed to present the necessary and also auxiliary radiological evaluations made before TKA in order to achieve better clinical results.
\end{abstract}

Keywords: Arthroplasty, Knee Joint, Radiography

\section{öz}

Total diz artroplastisi (TDA) semptomları azaltabilen ve eklem fonksiyonlarını eski haline getirebilen bir cerrahi yöntemdir. Bu operasyonun uzun vadeli başarısı, protez malzemesinin implantasyonu öncesinde doğru anatomik ve mekanik planlamaya bağlıdır. Doğru implant dizilimi ve anatomik denge, daha başarılı klinik sonuçlar ile protez materyalinin daha uzun süre kullanılabilmesini sağlar. Uygun olmayan preoperatif planlama, implantın gevşemesine ve diz ekleminde artan yüke neden olabilir. Konvansiyonel radyografiler bu amaçla en sık kullanılan görüntüleme yöntemidir. Bilgisayarlı tomografi ve manyetik rezonans görüntüleme ise gerekli durumlarda kullanılabilir. Ayrıca, bilgisayar destekli sistemler devreye girmiş ve başarılı sonuçlar bildirilmiştir. Komplike olmayan TDA sonrası erken radyografik değerlendirme gerekli değildir. Preoperatif görüntülemenin hastalığın ciddiyetini değerlendirmek, rezerv kemik dokusunu incelemek, ilgili anatomiyi gözden geçirmek, hangi implant ve cerrahi yaklașımın uygulanacağına karar vermek gibi birçok amacı vardır. Bu yazıda, daha iyi klinik sonuçlar elde etmek amacıyla TDA öncesi yapılan gerekli ve ayrıca yardımcı radyolojik değerlendirmeleri sunmayı amaçladık.

Anahtar kelimeler: Artroplasti, Diz Eklemi, Radyografi
Received/Geliş: 14.11 .2020

Accepted/Kabul: 04.12.2020

Publication online: 13.08 .2021

Sorumlu Yazar/

Corresponding Author:

Atilla Hikmet Cilengir

Basaksehir Cam and Sakura City

Hospital, Department of Radiology, Istanbul, Turkey

acilengir@gmail.com

ORCID: 0000-0002-4073-9665

S. Dursun 0000-0001-5105-6256 Hatay State Hospital, Department of Radiology, Hatay, Turkey

K.A. Sinci 0000-0002-2207-5850

O. Tosun 0000-0001-6755-2131 Izmir Katip Celebi University Ataturk Training and Research Hospital, Department of Radiology, Izmir, Turkey 


\section{INTRODUCTION}

Total knee arthroplasty (TKA) is an effective surgery that can help relieve pain and restore function in patients with severe osteoarthritis. One of the most important factors in the long-term success of this operation is to make correct planning before TKA. It is known that various factors including patient selection, surgical technique, implant design, and positioning and soft tissue balancing affect the outcome of TKA. The achievement of accurate implant alignment and ligament balance is very important. ${ }^{1,2}$ Deviations from the mechanical axis (MA) that line from femoral head to the center of the knee and ankle joints will lead to the increase in the risk of implant loosening and load on joint. Improper positioning of the components in the coronal plane during surgery will lead to acceleration of prosthesis wear and poor clinical outcome. $^{3}$

The restoration of mechanical axis and achievement of proper knee alignment and implant positioning that will result in more successful TKA outcomes and also extend the life of the prosthesis are very important issues. The aim is the realization of $180^{\circ}$ mechanical axis and $5-7^{\circ}$ tibiofemoral angle with

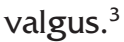

Preoperative and postoperative imaging is essential in planning and following the surgical procedure. The aim of the preoperative imaging is to assess the severity of the disease and the reserve bone tissue, to review the relevant anatomy, to decide which implant and surgical approach will be applied. Correct implant selection with proper size is one of the important stages in preoperative planning. Patient's and surgeon's expectations should be taken into consideration preoperatively to improve the outcomes and increase the postoperative satisfaction level. Conventional radiographs are the most frequently used imaging methods, but computed tomography (CT) and magnetic resonance imaging (MRI) may be used in required cases. Recently, computer-aided systems have come into use and quite successful results have been reported..$^{4-8}$ Early repetitive radiography is unnecessary after an uncomplicated cemented hip or knee arthroplasty for osteoarthritis. ${ }^{8}$

For a deeper understanding of the role of radiology in TKA, one should have a deep insight into the axes of the lower limbs associated with the knee, the angles between the axes, their direct radiography positions, templating of radiographs, downsides and upsides of CT and MRI as well as the significance of computer-aided systems. In this article, we aim to share the radiological evaluations made before the TKA operation in order to provide better clinical results.

\section{Lower limb axes associated with the knee}

1. Femoral anatomical axis: Line connecting the mid-femoral diaphysis and midpoint of the intercondylar notch of the femur (Figure 1).

2. Tibial anatomical axis: Line connecting the midpoint of tibial eminences and the midpoint of talus dome (Figure 1).

3. Femoral mechanical axis: Line connecting the center of the femoral head to the intercondylar notch of the femur (Figure 2).

4. Tibial mechanical axis: Same as the tibial anatomical axis (Figure 2).

5. Lower limb anatomical axis is formed by connecting the tibial and femoral anatomical axes.

6. Lower limb mechanical axis: Line connecting the center of the femoral head and the center of the ankle (Figure 3).

7. Transtibial axis: Line drawn tangentially to the medial and lateral tibial plateaus ${ }^{2,4}$ (Figure 4a).

8. Transcondylar axis: Line drawn tangentially to the ends of the medial and lateral condyles of the femur in the knee joint (Figure 4b).

\section{Knee angles}

1. Hip-knee-ankle angle: The angle between the femoral and the tibial mechanical axes. The angle is normally $180^{\circ}$. It is above $180^{\circ}$ in the case of a valgus, and less than $180^{\circ}$ in the case of a varus deformity (Figure 2).

2. Femorotibial angle: The angle between the femoral and tibial anatomical axes. Normally, the tibia is $9^{\circ}$ in short people, $5^{\circ}$ in tall people, with an average of $7^{\circ}$ of the valgus relative to the femur (Figure 1).

3. Lateral distal femoral angle: The lateral angle between the line drawn tangentially to the ends 


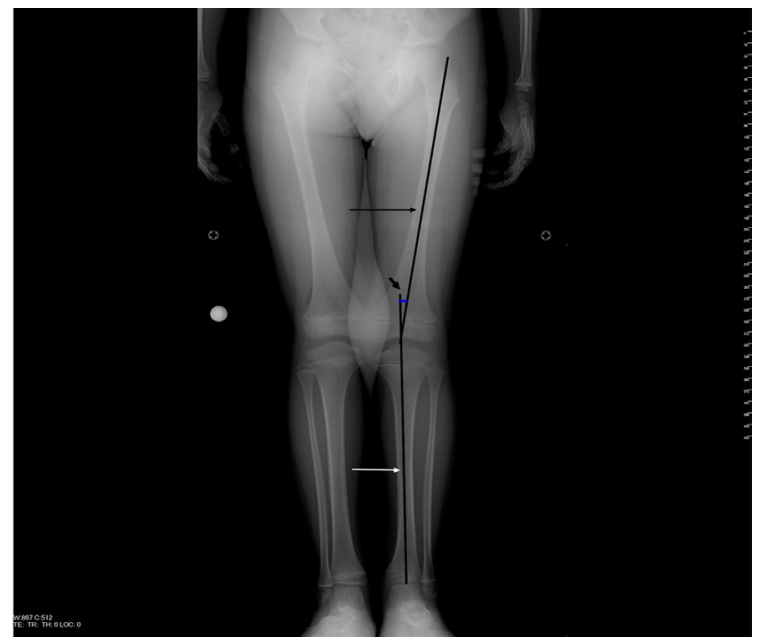

Figure 1: Standing anteroposterior radiograph of the lower leg shows the femorotibial angle (short black arrow) which is between the femoral (long black arrow) and tibial (long white arrow) anatomical axes.

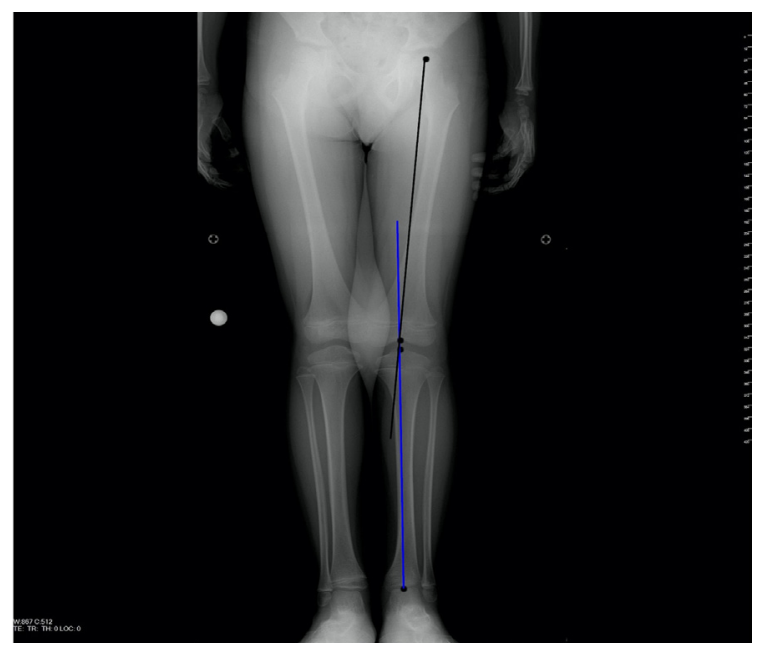

Figure 2: Standing anteroposterior radiograph of the lower leg shows the hip-knee-ankle angle formed between femoral (black line) and tibial mechanical axes (blue line).

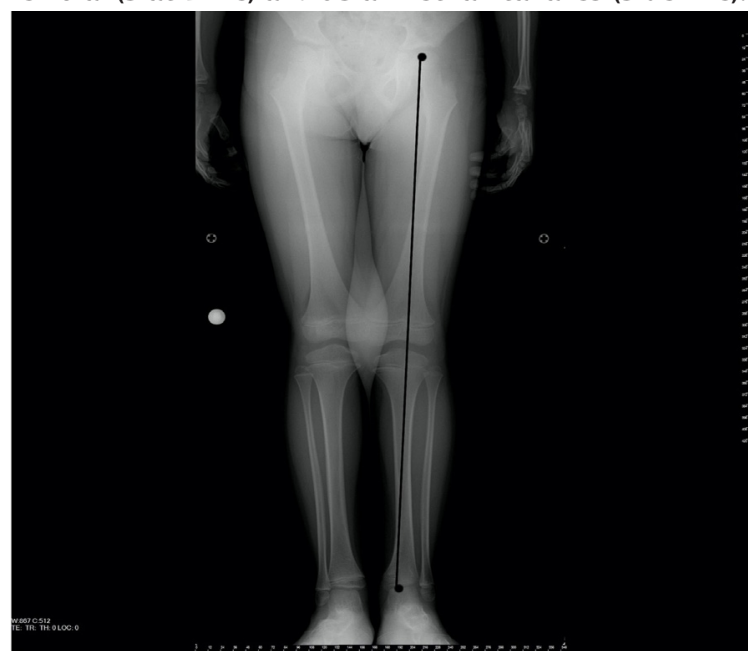

Figure 3: Standing anteroposterior radiograph of the lower leg shows lower limb mechanical axis.

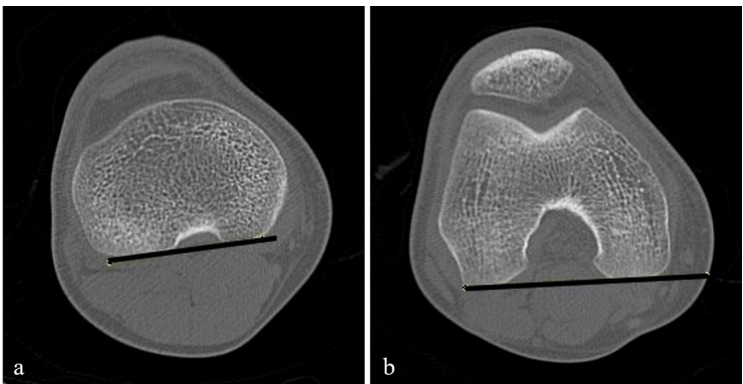

Figure 4: Transtibial (a) and transcondylar (b) axes are drawn on the axial computed tomography slices.

of the medial and lateral condyles of the femur in the knee joint (transcondylar axis) and the femoral mechanical axis. This angle is normally $87 \pm 2^{\circ}$.

4. Medial proximal tibial angle: The medial angle between the line drawn tangentially to the tibial plateaus and the tibial mechanical axis. This angle is normally $87 \pm 2^{\circ}$.

5. Tibiofemoral divergence: The angle between the line drawn tangentially to the ends of the medial and lateral condyles of the femur in the knee joint (transcondylar axis) and the line drawn tangentially to the tibial plateaus (transtibial axis). Normally, these two lines converge medially. An angle between $0.4^{\circ}-3^{\circ}$ is considered to be normal. Its mean value is $1.7^{\circ}$.

6. Posterior tibial slope angle: The angle between the line drawn perpendicular to the long axis of the tibia in lateral radiographs and the line drawn parallel to the medial tibia plateau. Its mean value is $10^{\circ}$. 4-6

\section{Radiographic examination}

1. Weightbearing hip-ankle radiographs: Standing weightbearing hip-ankle radiographs, which determine the mechanical axis of the lower limbs are the gold standard methods in the assessment of coronal plane alignment ${ }^{3,9,10}$ (Figures 1, 2 and 3). Standing anteroposterior radiographs allow to determine whether there will be significant bone loss during surgery and to decide whether such bone loss will need to be compensated. A vertical horizontal line is drawn from the unaffected plateau region to the long axis of the tibia. No specific action will be required if maximal bone loss did not reduce the height of the affected plateau above $15 \mathrm{~mm}$ compared with a normal plateau. Standing radiographs also allow for the measurement of the amount of subluxation and ligamentous laxity positioned medial and lateral 


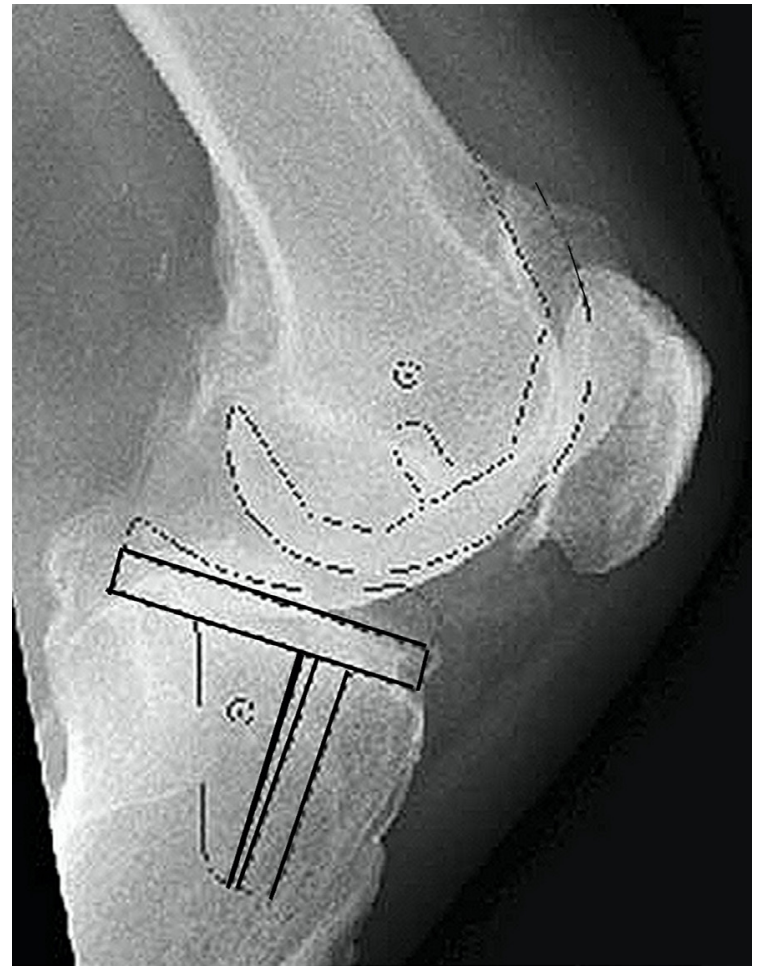

Figure 5: Preoperative templating radiograph of a osteoarthritic knee joint.

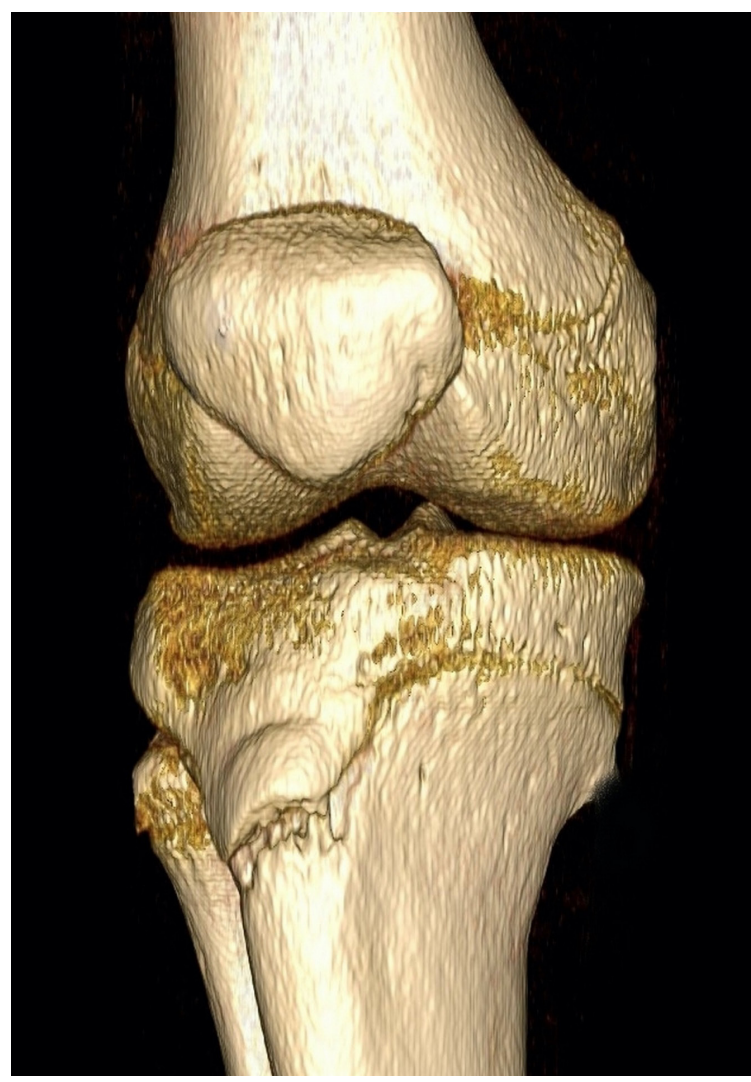

Figure 6: Three-dimensional computed tomography examination of the knee joint using volume rendering technique. to the knee. They also allow for the determination of the sizes and locations of the osteophytes that need to be removed while reconstructing the anatomical contours of the knee during surgical procedure. ${ }^{11}$

2. Weightbearing knee anteroposterior radiographs: They are cheaper and easier alternatives to weightbearing hip-ankle radiographs. A comparative study that examined the two methods has concluded that both radiographic methods allowed a reliable and accurate measurement of tibiofemoral angle and alignment of the implant. However, where lower limb malalignment is suspected, hip-ankle radiographs have been reported to yield more accurate estimates about the mechanical axis. ${ }^{3}$

3. Standing posteroanterior Rosenberg radiographs (taken with the knee in $45^{\circ}$ of flexion): They help to identify the hypoplastic posterior femoral condyles particularly in knees with valgus deformity by comparing standard standing anteroposterior radiographs of both knees. ${ }^{12}$

4. Lateral and patellar radiographs: They are important for preoperative planning. Patellar images allow to identify patellar thinning common particularly in valgus deformities and erosive changes. Lateral radiographs are also very important in better imaging large posterior osteophytes and in identifying whether there is any sequela of patella baja from a previous osteotomy or arthroscopic procedure. ${ }^{12}$

Templating of radiographs

Preoperative templating of the radiographs allows for the accurate determination of the size and position of the implants when preparing the patient for surgery. Accurately sized implants help maintain the soft tissue balance and ensure an even load transmission on the new joint. Templating of radiographs (Figure 5) will allow for the determination of various sizes of implants that would require a special order, and the estimation of size mismatches between femoral and tibial implants. If noticed earlier, such restrictions can be eliminated during surgery or different implant systems can be chosen. ${ }^{13}$

Analyses, which could be performed using standard radiographs, transparent papers and/or 
transparent plastic templates, are now supplemented by digital templating of radiographs. ${ }^{2}$ Standard preoperative templating of radiographs is performed by taking measurements of knee implants using acetate templates on magnified standard AP and lateral radiographs. ${ }^{13} \mathrm{~A}$ method where the templates are electronically applied from the digital memory, the technique of digital templating of radiographs has been recently applied at certain clinics. Availability of numerous templates, speed and accuracy, elimination of printed radiographs and reduced costs are some of the upsides of digital templating. Its downsides include its dependence on digital memory, high costs of software and software design restrictions. 2,13,14

Some problems may be encountered during templating using analog films. The most important problem is the inaccurate determination of the magnification factor resulting from the radiography technique. Knee radiographs are taken at one meter away from the film cassette. Image magnification is proportional to the distance between the bone and the cassette. Magnification is typically $110 \%$ and may be affected by the distance between the bone and the cassette. Increased soft tissue thickness and skin contractures may increase the distance of the bone to the cassette, resulting in an increased magnification factor. So, placing markers with certain sizes equally distanced to the bone and the cassette allows for the accurate estimation of the magnification factor in all images. ${ }^{13,15}$ Typically, standard magnification templates are used. However, this may not be adequate in correcting the magnification factor. One way to troubleshoot this problem is the use of digital radiography which has replaced conventional radiography. Thus, magnification can be corrected, and operational problems can be eliminated with a two-dimensional projection of the threedimensional structure. Digital images can be corrected by using calibration objects. However, if the place of the calibration object differs much from the observed region, it should be remembered that digital correction of magnification can also cause structural errors. ${ }^{16}$ One other method to troubleshoot the magnification problem is the use of CT images. However, routine use of CT will increase both radiation dose exposure in patients and the cost of radiological examinations. In addition to the filming technique, increased magnification and distortion caused by tibial rotation contractures in the flexion and extension could also ensue in inaccurate results in preoperative templating of anteroposterior radiographs. In such cases, it could be more reasonable and beneficial to use lateral radiographs in determining implant sizes and borders. Considering the downsides in radiographic planning, one should remember that the ultimate size of implant components needs to be determined based on the sizes of femur, tibia and patella estimated during surgery. ${ }^{12}$

\section{CT and MRI}

CT and MRI are not routinely used in the preoperative planning of TKA. CT may be useful in visualizing the spread of cystic changes in osteoarthritis. Bone reserves can also be assessed by plain radiographs or CT. Differences between the lengths of both legs can also be accurately assessed by CT. However, routine use is not recommendable considering the radiation dose exposure and the cost of the procedure. ${ }^{17} \mathrm{~A}$ typical CT examination of the pelvis exposes the patient to a radiation dose of about $10 \mathrm{mSv}$, which is 10-15 times more than the dose exposure from direct radiography and is equivalent to about 4.5 years of background radiation. However, since image quality issues, magnification errors and orientation uncertainties associated with standard radiographs reduce their value in preoperative planning, threedimensional images have been obtained by changing CT imaging protocols and reducing radiation dose exposures. By reducing both the size of scanned body area and the radiation dose exposure, images that could produce reliable three-dimensional data in doses between 0.53$0.84 \mathrm{mSv}$ were obtained without significant loss in bone image quality (Figure 6). This suggests that CT images can be used more frequently in the future. ${ }^{18}$

MRI is also rarely used in preoperative planning. MRI can be used especially in patients with 
avascular necrosis in order to assess the severity of the disease and understand whether it is found on both sides. ${ }^{17}$ The length of time needed for examinations and the cost of procedure are among the factors restricting its use.

\section{Computer-Aided Systems}

In certain cases, it is not possible to accurately size the femoral component and choose appropriate implants just by using anteroposterior and lateral radiographs. Recently, there has been too many developments covering the determination of mechanical alignment during TKA and the positioning of components. Latest innovations include computer-aided systems. Interactive three-dimensional reconstruction models are increasingly used in simulating surgical procedures and designing implants. ${ }^{1}$

Using computer-aided systems, the exact size of the femoral component can be measured regardless of alignment deformities or the patient's position and real-time extramedullary data can thus be obtained. There are also reports suggesting that these systems are very useful in achieving reliable and highly repeatable coronal alignment. ${ }^{1,719}$

There are several types of computer-aided systems including the already used non-imaging systems based on fluoroscopy or CT. In such systems, a navigational tool creates a model of the patient's knee and then determines which bone incision will give an ideal mechanical axis (neutral or 0 degrees). In CT-based systems, actual CT data of the patient's limb are transferred to the navigation computer and then a model of the patient's lower limb is created based on such data. In the fluoroscopy-based system, fluoroscopy is intraoperatively used in order to create the patient's anatomical model. The nonimaging method is the most commonly used modality in knee replacement surgery. Here, the mechanical axis and the knee model are determined by intraoperatively measuring hip joint rotation range of motion and by identifying the bones in the ankle and knee regions. ${ }^{4}$ Despite their lengthy preoperative assessment times and costly intraoperative imaging stages, CT-based systems offer detailed three-dimensional anatomical data about sagittal and axial alignment. Multiplanar images created using the CT data of patients and computer-aided system files of existing implants help to decide on the size and position of the implant to be used. ${ }^{6,19}$

Computer-aided systems are continually improving. There are significant increases in successful TKA surgeries thanks to such innovative technologies. However, considering the dramatic increase in resulting operational costs due to hardware, disposable materials and extended surgery times, they are not expected to be routinely used in the near future. ${ }^{4}$

\section{CONCLUSIONS}

Preoperative radiological evaluation of knee joint is beneficial for assessing clinical outcomes in TKA candidates. In this way, joint mechanics can be properly evaluated, and implant complications can be avoided. Standing radiographs of the lower leg are the most commonly used radiological methods. CT, MRI and computeraided systems are helpful in certain cases. Preoperative templating of the radiographs provides accurate determination of the size and position of the implants. With the knowledge of these methods, it is possible to ensure better operative results.

Conflict of Interest: None

Funding: None

Informed Consent: Not applicable

\section{REFERENCES}

1. Lee IS, Choi JA, Kim TK, Han I, Lee JW, Kang HS. Reliability analysis of $16-M D C T$ in preoperative evaluation of total knee arthroplasty and comparison with intraoperative measurements. AJR Am J Roentgenol. 2006;186:1778-1782. doi: 10.2214/ AJR.05.1191.

2. Jamali AA. Digital Templating and Preoperative Deformity Analysis with Standard Imaging Software. Clin Orthop Relat Res. 2009;467:26952704. doi: 10.1007/s1 1999-009-0858-y.

3. Skyttä ET, Lohman $M$, Tallroth $K$, Remes V. Comparison of standard anteroposterior knee and hip-to-ankle radiographs in determining the lower limb and implant alignment after total knee 
arthroplasty. Scand J Surg. 2009;98:250-253. doi: 10.1177/145749690909800411.

4. O'connor MI. Computer assisted Navigation in total knee arthroplasty. Northeast Florida Medicine. 2006;57:18-20.

5. Paley D, Maar D, Herzeber JE. New consepts in high tibial osteotomi for medial compartment osteoarthritis. Orthop Clin North Am. 1994;25:483497.

6. Coventry MB. Upper tibial osteotomy for gonarthrosis. The evolution of the operation in the last 18 years and long term results. Orthop Clin North Am. 1979;10:191-210.

7. Huang TW, Lee CY, Lin SJ, et al. Comparison of computer-navigated and conventional total knee arthroplasty in patients with Ranawat type-II valgus deformity: medium-term clinical and radiological results. BMC Musculoskelet Disord. 2014;15:390. doi:10.1186/1471-2474-15-390.

8. Niskanen RO. Early repetitive radiography is unnecessary after an uncomplicated cemented hip or knee arthroplasty for osteoarthritis. Acta Orthop Belg. 2005;71:692-695.

9. Berend ME, Ritter MA, Meding JB, et al. Tibial component failure mechanisms in total knee Arthroplasty. Clin Orthop Relat Res. 2004;428:2634. doi: 10.1097/01.blo.0000148578.22729.0e.

10. Ritter MA, Faris PM, Keating EM, Meding JB. Postoperative alignment of total knee replacement. Its effect on survival. Clin Orthop Relat Res. 1994;299:153-156. https://doi.org/10.1097/00003086-199402000-00021

11. Lothke PA. Primary total knees. In: Lothke PA, Lonner JH, Buechel FF, editors. Master techniques in orthopaedic surgery. Knee arthroplasty. $2^{\text {nd }}$ ed. Lippincott Williams \& Wilkins; 2003, p. 49-72.

12. Buechel FF. Lateral Approach. In: Lothke PA, Lonner $\mathrm{JH}$, Buechel FF, editors. Master techniques in orthopaedic surgery. Knee arthroplasty. 2nd ed. Lippincott Williams \& Wilkins; 2003, p. 15-27.
13. Specht LM, Levitz S, Iorio R, Healy WL, Tilzey JF. A comparison of acetate and digital templating for total knee arthroplasty. Clin Orthop Relat Res. 2007;464:179-183.

https://doi.org/10.1097/BLO.0b013e3181560d74

14. Lewis J, Hossain M, Mustafa A, Sinha A. Comparison of digital and plain radiography preoperative templating in total knee arthroplasty. Eur J Orthop Surg Traumatol. 2008;18:357-360. doi:10.1007/ s00590-008-0313-x

15. Conn KS, Clarke MT, Hallett JP. A simple guide to determine the magnification of radiographs and to improve the accuracy of preoperative templating. J Bone Joint Surg Br. 2002;84:269-272. doi: 10.1302/0301-620x.84b2.12599.

16. The B, Diercks RL, van Ooijen PM, van Horn JR. Comparison of analog and digital preoperative planning in total hip and knee arthroplasties. A prospective study of 173 hips and 65 total knees. Acta Orthop. 2005;76:78-84. doi: 10.1080/00016470510030364

17. Ali S, Reinus WR. Imaging of Prosthesis. In: Bonakdarpour A, Reinus WR, Khurana JS, editors. Diagnostic imaging of Musculoskeletal Diseases. A systematic approach. Springer; 2010, p. 497-496. https://doi.org/10.1007/978-1-59745-355-4_12

18. Henckel J, Richards R, Lozhkin K, et al. Very lowdose computed tomography for planning and outcome measurement in knee replacement. The imperial knee protocol. J Bone Joint Surg Br. 2006;88:1513-1518.

doi: 10.1302/0301-620X.88B11.17986

19. Hananouchi T, Nakamura N, Kakimoto A, Yohsikawa $\mathrm{H}$, Sugano N. CT-based planning of a single-radius femoral component in total knee arthroplasty using the ROBODOC system. Comput Aided Surg. 2008;13:23-29. doi: $10.3109 / 10929080701882580$. 